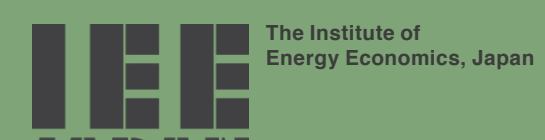

\title{
JapaIII
}

\section{Finding a Viable Path to Reducing Greenhouse Gas Emissions}

K. Akimoto, J. Arima, M. Babiker, M. Caine, D. Hobbs, E. Korhola, A. Sieminski, N. Stehr, H. Tezuka, M. Toyoda, and E. Williams 


\section{Acknowledgments}

The authors would like to thank Douglas Cooke, Saleh Muhanna and Wolfgang Heidug for their insightful contributions. The authors are also grateful to the United States Chamber of Commerce and the Research Institute of Innovative Technology for the Earth, Japan, for hosting meetings that helped inform the contents of this paper.

\section{About KAPSARC}

The King Abdullah Petroleum Studies and Research Center (KAPSARC) is a non-profit global institution dedicated to independent research into energy economics, policy, technology and the environment across all types of energy. KAPSARC's mandate is to advance the understanding of energy challenges and opportunities facing the world today and tomorrow, through unbiased, independent, and high-caliber research for the benefit of society. KAPSARC is located in Riyadh, Saudi Arabia.

\section{Legal Notice}

(C) Copyright 2019 King Abdullah Petroleum Studies and Research Center ("KAPSARC"). This Document (and any information, data or materials contained therein) (the "Document") shall not be used without the proper attribution to KAPSARC. The Document shall not be reproduced, in whole or in part, without the written permission of KAPSARC. KAPSARC makes no warranty, representation or undertaking whether expressed or implied, nor does it assume any legal liability, whether direct or indirect, or responsibility for the accuracy, completeness, or usefulness of any information that contain in the Document. Nothing in the Document constitutes or shall be implied to constitute advice, recommendation or option. 


\section{Key Points}

The greenhouse gas (GHG) reductions pledged in the latest nationally determined contributions (NDCs), as part of the Paris Agreement, are insufficient to reach climate stabilization targets.

Many countries, especially those with developing economies, are reluctant to commit to significant GHG reductions without a clear path to the development of low-cost, low-carbon technology.

Developing an array of low-carbon technologies creates options, as it is unclear exactly what the optimal low-carbon technological path will be.

Broadening NDCs to include technological collaboration and a global technology commons could provide an incentive to develop low-cost, low-carbon technologies.

Allowing countries that sell emissions-reducing products and technologies to account in their own NDCs for some share of the emissions reductions resulting from the end use of their technologies could provide a further incentive for technological development.

A holistic approach to technology development is essential. Such an approach would take advantage of the power of markets to drive innovation while implementing policies that internalize externalities and provide research and development push and market pull at key points along the innovation pathway. 
A viable, least-cost pathway to a low greenhouse gas (GHG) emissions future must lie within the United Nations Framework Convention on Climate Change (UNFCCC) Paris Agreement. The rulebook for the Agreement was in many ways rewritten at the 2018 United Nations Climate Change Conference (COP24) in Katowice, Poland. The flexible nature of the Agreement allows the international community to shift course as necessary.

The 2018 Emissions Gap Report of the United Nations Environment Programme estimates that the current contributions of the 175 'Parties' to the Paris Agreement are inadequate to bridge the emissions gap by 2030 and meet the Paris goal of a maximum increase in global average temperature of 2 degrees Celsius $(C)$ compared with the pre-industrial era (UNEP 2018).

Total annual GHG emissions reached 53.5 gigatonnes of carbon dioxide-equivalent (CO2e) in 2017. The Report estimates that countries' current contributions would lower global emissions in 2030 by only up to 6 Gt CO2e compared with a continuation of current policies and would allow emissions to grow in absolute terms to 59 Gt CO2e. It concludes that the current level of ambition needs to be roughly tripled for the $2^{\circ} \mathrm{C}$ goal to be met and increased fivefold to achieve the $1.5^{\circ} \mathrm{C}$ scenario.

Against this background, Parties have pledged to submit updated nationally determined contributions (NDCs) as part of a global stock-take process set to take place every five years, beginning in 2023. The UNFCCC process will consider the latest scientific evidence available and provide an opportunity for Parties to correct course, if necessary, in order to enhance or update their bottom-up commitments as pledged through their NDCs. Given that Parties' individual pledges drive collective action, the Agreement provides an opportunity to adjust both the stringency and the nature of actions pledged to meet climate goals.

This paper offers a viable and meaningful path to GHG emissions reduction. It outlines the challenge of developing economies to continue their economic growth while meeting internationally agreed climate goals and reveals the need for low-cost, low-carbon technologies. For these low-carbon technologies to be readily available and cost-effective, this paper recommends like-minded Parties to the Agreement tailor their NDCs to meet the following goals:

Create additional opportunities for participants to gain recognition for contributions to the global low GHG-emitting technology commons. This would offer an incentive for making intellectual property available at a reasonable cost to those who can least afford to pay.

Balance the roles of governments and the private sector in supporting energy innovation by leveraging reliable, well-functioning energy markets to reduce the costs of low-emissions technologies. Well-functioning markets, in this context, are those that reflect external costs (i.e., the costs of damages arising from climate change) and achieve the meaningful goal of climate stabilization. A meaningful well-functioning market goes beyond the narrow definition of markets as places for buyers and sellers to freely exchange goods and services, incorporating appropriate technology incentives to achieve societal aims. 


\section{Discussion}

\section{Identifying alternative} strategies to engage developing economies

Continuing global economic growth and development is crucial for the fair and equitable advancement of human welfare, as expressed in the United Nations (U.N.) sustainability goals. This economic growth, in turn, is dependent on maintaining and extending access to affordable and reliable modern energy services while also expanding energy for productive uses.

According to the International Energy Agency, two trends have emerged recently for energy access. First, the number of people per year gaining access to electricity has grown from 62 million in the period 2000-2012 to over 100 million since 2012 (IEA 2017). Second, the share of renewable energy in providing electricity access is increasing (Figure 1) (IEA 2017).

Great strides have been made in improving electricity access globally. From 2000 to 2016, the number of people without access dropped from 1.67 billion, or $27 \%$ of the world's population, to 674 million, or $14 \%$ of the population (IEA 2017). India has been the most successful country in improving electricity access. From 2000 to 2016, the proportion of India's population without access fell from $57 \%$ in 2000 to $18 \%$ in 2016 (IEA 2017), while the country's population grew by 286 million (World Bank 2019). In 2016, the world's largest population without electricity, 588 million, was in

Figure 1. Number of people per year gaining access to electricity globally, by source.

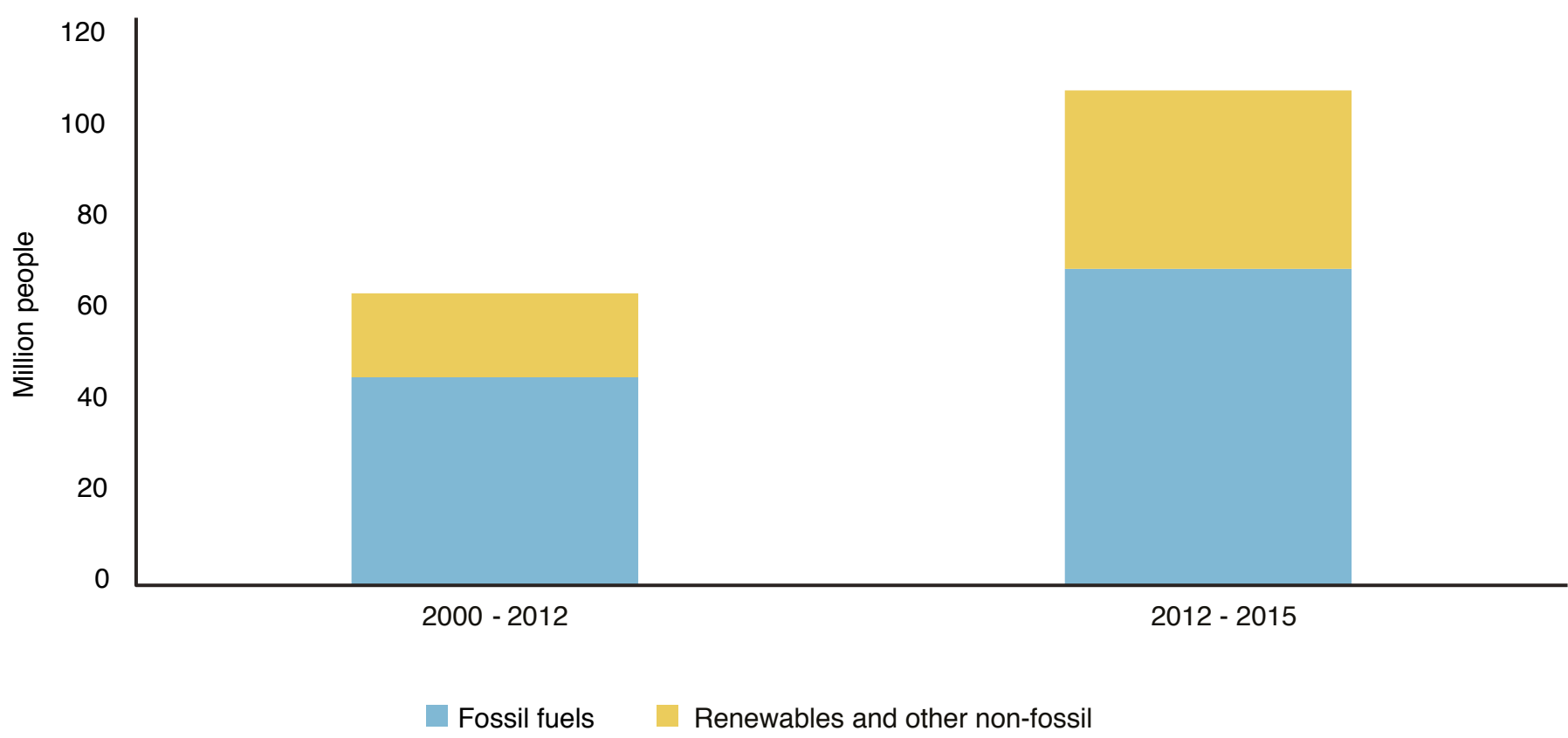

Source: IEA (2017). 
Sub-Saharan Africa (SSA) (IEA 2017). In 2014, the number of people gaining access to electricity in SSA finally outpaced its population growth, after a significant upswing in efforts by many governments, and national and international organizations to provide access. Since 2012, 26 million people per year in SSA have gained access to electricity, compared with 9 million per year from 2000 to 2012 . The mix of new capacity in SSA since $2012-70 \%$ renewables and $30 \%$ fossil fuels - has also changed substantially from the 2000 to 2012 period, when it comprised $42 \%$ renewables and $58 \%$ fossil fuels (Figure 2) (IEA 2017).

Those in SSA still without electricity access are generally located in remote areas. In large part, they do not have access because the cost of extending the grid is prohibitive. Cost reductions in solar photovoltaic (PV) generation and battery technology have made solar home systems and solar microgrids a lower-cost option for most remote areas of the world than extending central grids. If these trends continue, then providing more access is unlikely to result in significant increases in $\mathrm{GHG}$ emissions.

However, adding more electricity-generating capacity to central grids in developing economies to drive economic growth could generate high levels of GHG emissions. If unabated, this new capacity could create climatic conditions that may jeopardize future growth and prosperity. Hence the key challenge remains to provide affordable and reliable energy services in an environmentally sustainable and responsible manner. Climate policy needs to be understood and addressed as part of an integrated approach to national and global socioeconomic challenges, with all the inherent tradeoffs that this implies.

Figure 2. Number of people in SSA per year gaining access to electricity, by source.

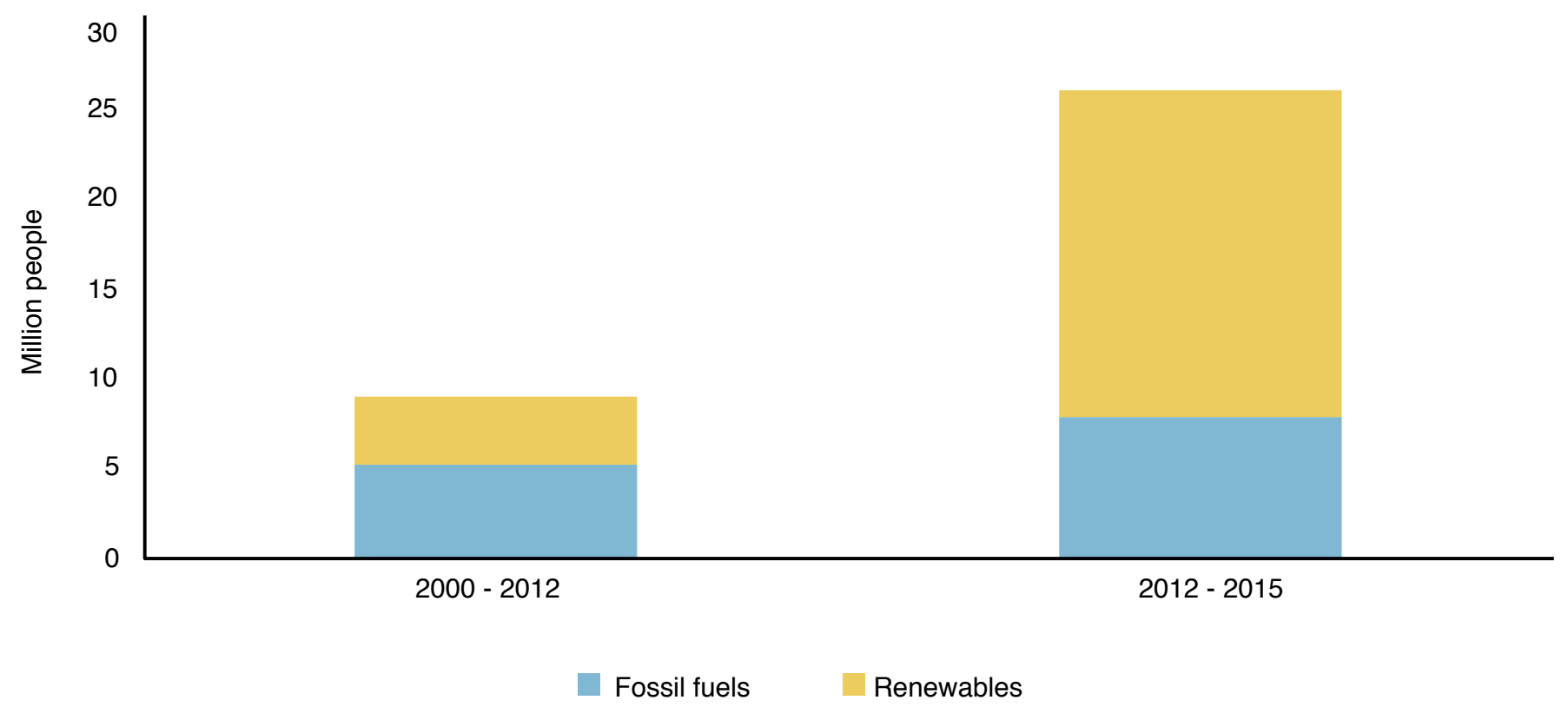

Source: IEA (2017). 


\section{Nationally determined contributions and national development goals}

The NDCs offered under the Paris Agreement stem from the respective national development goals (NDGs). These NDGs provide a useful framework for analyzing countries' climate change priorities. While the U.N. sustainable development goals (SDGs) apply to all countries, the NDGs are individual country goals based on national circumstances and indigenous resources. In short, they offer a more precise metric, because the 17 sustainable development priorities of the SDGs could rank very differently among developing countries.

Larger non-OECD (Organization for Economic Cooperation and Development) countries such as China, India, Brazil and South Africa committed to more ambitious NDCs than poorer ones. By contrast, the hydrocarbon-rich member countries of the Gulf Cooperation Council (GCC) proposed NDCs largely based on economic diversification and adaptation to climate change policy responses, while hydrocarbon-poor economies such as Morocco based their NDCs on the deployment of renewables. This contrast reflects the differences in the availability and type of natural resources.

The inherently uncertain and complex nature of the climate change challenge, combined with our ever-evolving understanding of its likely impacts, suggests the need for a flexible and adaptable policy approach as embodied by the Paris Agreement. The global stock-take process enables a timely response to an evolving understanding of climate science, to technological advances, changes in costs and market-driven innovation and evolving community expectations. Governments have a key role to play to lead an efficient, innovative, timely and least-cost response that balances these goals.

\section{Enabling the transition requires a cost-effective suite of low- or zero-emissions technologies}

All previous energy transitions have proceeded slowly and have involved moving from lower to higher density energy sources. The current transition often seeks to reverse this process by moving from a reliance on the high-density fossil energy that underpins modern economic growth and prosperity to mostly low-density renewable energy. This risks making the transition more challenging if the range of options does not include environmentally sustainable approaches to the consumption of hydrocarbons. Access to a cost-effective suite of low- or zero-emissions technologies will be a key enabler of the transition.

Understandably, developing economies prioritize economic development as a means of generating wealth and improving their populations' standard of living, including energy access. Experience shows that as these economies grow and mature, their capacity to afford and undertake emissions reduction should increase. In the shorter - term, however, increasing emissions may be inevitable without viable low-cost technology options.

Regardless of one's position on questions of historical social justice raised by many in developing economies, it is pragmatic to accept that without financial assistance from richer economies, poorer societies will invest in certain and immediate needs before they can afford the luxury of investing in future welfare. 


\section{Reducing GHG emissions requires a global, holistic approach}

Climate change is a global problem, requiring governments to look beyond their national borders. A globally integrated, holistic, solution is needed to reduce GHG emissions. A holistic approach can give developed economies an incentive to drive reductions internationally through commercial innovation and the transfer of new low-emitting technologies to developing countries. A globally integrated approach prioritizes GHG emissions reduction in the global value chain, while also driving cost-effective emissions in the economies producing the technologies central to that value chain.

The U.N. NDC approach certainly has value in driving domestic policies, even in the absence of binding obligations between the Parties. It creates greater public awareness of the roles countries are playing and moves the conversation forward to prepare the ground for further steps toward the goal of mitigating climate change.

The gap between cumulative NDCs and the necessary global mitigation pathway suggests a need for new low-cost, low-carbon technologies because many countries fear that GHG mitigation efforts will damage their economic growth. Governments can play a crucial role in crafting policy to foster technological development. The first role for policy is during the research and development stage in which many promising paths are explored at considerable cost, but only a relative few go on to be commercially viable. The other role for policy is during the 'death valley,' after a technology has been proven in a pilot phase and before the commercialization stage. Crossing this valley is difficult without policy incentives because the risks of scaling up for commercial production without demonstrated market demand may limit private investment. Creating a clear and long-term demand for low-carbon technologies through the use of market mechanisms helps near-commercial technologies become commercial. It also shows private investors the potential rewards of investing in research and development (R\&D).

\section{Investing in a wide range of cost-effective low- and zero-emissions technologies will create options}

Best guesses about how the future will unfold will most likely be wrong. We do not know with certainty what climate impacts will occur, when they will happen, how severe they will be, and exactly how many tonnes of GHG reductions are needed to avoid them. This is not to say that uncertainty should give pause to action; revisions to the science are consistently in one direction - impacts are more severe and are happening more quickly than scientists previously predicted. We also do not know what the relative costs and characteristics of existing low-carbon technologies will be, or what new technologies might be available. Perhaps a 'silver bullet' technology that solves the climate problem, such as inexpensive low-energy direct air carbon capture, will be developed. Perhaps it will not. A group of technologies that is likely to perform well under a variety of possible futures has greater value than a single 'blockbuster' technology that works well only when dozens of uncertain outcomes fall into place as hoped.

Rather than prematurely trying to pick technology winners, success lies in creating options investing in a wide range of technologies, including the cleaner use of fossil fuels; carbon capture storage and utilization; renewable energy; energy 
storage; hydrogen; energy efficient demand-side technologies; 'smart' grids and controllable devices; and nuclear power.

\section{Giving incentives to contribute to a global 'low GHG-emitting technology commons'}

In addition to the proven technology push and market pull policies that some countries have focused on, another promising approach to technology policy would be international and cooperative, in which countries pledge access to their technologies that contribute to global emissions reduction. Meeting these pledges might require lower-cost access to intellectual property than has been the case historically and removing barriers to transferring technology know-how and capacity building. This could lead to the creation of other complementary 'virtue rankings,' in which developed economies are given an incentive to effect positive reductions internationally through recognition of their contribution to a global low GHG-emitting technology commons.

These contributions are credited as contributing to reducing GHG emissions through the creation of GHG-neutralizing value chains or technology development. Since these contributions simply provide a different way of slicing the aggregate outcome, double counting or overlapping with reductions outlined in the NDCs does not matter. What ultimately matters is the extent of global emissions reduction.

\section{Expanding the NDCs: The value of international collaboration in developing new technologies}

While countries that have developed innovative technologies deserve some accolade, those that deploy them in their energy systems deserve credit as well. In other words, a holistic approach focuses on the contribution made by technologies to emissions reduction no matter where it occurs; NDCs need not have a narrow focus on emissions reduction, recognized only within national borders. In fact, NDCs can consist of a variety of contributions that result in indirect carbon reductions. There is value in offering additional options that contribute to a solution to address a global problem through international collaboration, rather than sticking to national solutions. This should help to avoid unnecessary conflicts between developed and developing economies, between countries with high and low mitigation costs, and to avoid affecting any countries too focused on 'national numbers.'

We need to go beyond NDCs and appreciate the value of international collaboration in developing new technologies and deploying those technologies in developing countries. The consideration of such a holistic approach is not new. For example, support for technology transfer is integral to the UNFCCC process. Clean technology transfer and deployment have been institutionalized under the Technology Mechanism, incorporating the Technology Executive Committee (UNFCCC) and the Climate Technology Center and Network (CTCN). Similarly, several global industry associations have recognized the importance of climate technology transfer and global sharing of best practices along with technology innovation. 


\section{Example of best practice sharing - The World Steel Association (WSA 2018)}

The World Steel Association promotes an understanding of four aspects of its approach, the GHG footprint of steelmaking activities, through such publications as its fact sheet "Climate change mitigation by technology, innovation and best practice transfer." These four aspects are:

1) It will continue to use Carbon as a reducing agent, but the $\mathrm{CO}_{2}$ produced will need to be captured and stored. The approach is similar to the power industry's effort to cut emissions from fossil fuel-based power plants, but the steel production solutions include a maximum use of scrap, best practice operations and $\mathrm{CO}_{2}$ capture for storage.

2) It will use Hydrogen as a reducing agent to replace carbon because, when it is combusted, it produces only water vapor. Hydrogen, either pure or as a synthesis gas (syngas) through reforming methane or natural gas, can be used in conventional direct-reduction reactors or in more futuristic flash reactors.

3) Biomass can be used to generate the reducing agent (carbon), either from charcoal, for example, or syngas. It would need to be grown near the place of use and in sufficient quantities to make it economically viable and sustainable.

4) Carbon capture and storage (CCS) is a necessary process to achieve a large reduction in $\mathrm{CO}_{2}$ emissions. The $\mathrm{CO}_{2}$ can be stored or reused for purposes such as enhanced oil recovery.

\section{Promoting avoided emissions through the use of climate resilient products}

Sharing intellectual property and capacity building are not the only means by which countries can contribute to reducing GHG emissions. Selling products that generate efficiencies further through the value chain can also have a significant impact. If country $A$ sells products to country $B$ that result in lower emissions compared with alternative solutions, there may be some negative impact on country A's emissions since in many cases such environmentally superior products require more energy to produce. However, this increase in emissions in country $A$ is more than offset by the avoided emissions in country $\mathrm{B}$. Examples of this might include the use of advanced high-strength steel in the manufacture of automobiles, which then consume less fuel during their lifetimes as a result of their lighter weight.

The International Council of Chemical Associations promoted the concept of avoided emissions by using climate-resilient industrial products, and issued a guideline "Addressing the Avoided Emissions Challenge" that suggested how to account for the net benefits (ICCA 2013). A similar calculation/ methodology was developed by the World Steel 
Association in the case study of advanced highstrength steel's contribution to tail-pipe emissions reduction in automobiles.

The concept is now accepted by GHG Protocol, promoted by the World Resources Institute and the World Business Council for Sustainable Development. Industries are encouraged to calculate and report the avoided emissions environmentally superior products deliver.

This approach can help foster international cooperation through disseminating efficient and environmentally friendly technologies to developing countries. The use of products such as green information technology and high-performance steel would reduce global value chain-based GHG emissions. This approach would support the achievement of the U.N. sustainability goals while remaining consistent with the principles underpinning the Paris Agreement.

Creating multiple channels for recognition can help change public attitudes and give all citizens a stake in achieving carbon reductions. The Paris Agreement contemplates multiple ways of effecting $\mathrm{CO}_{2}$ emissions reduction, and this approach could certainly be among them, as illustrated in figure 4 .

Figure 4. International cooperation and technological innovation: An integrated, holistic approach to global GHG emissions reductions.

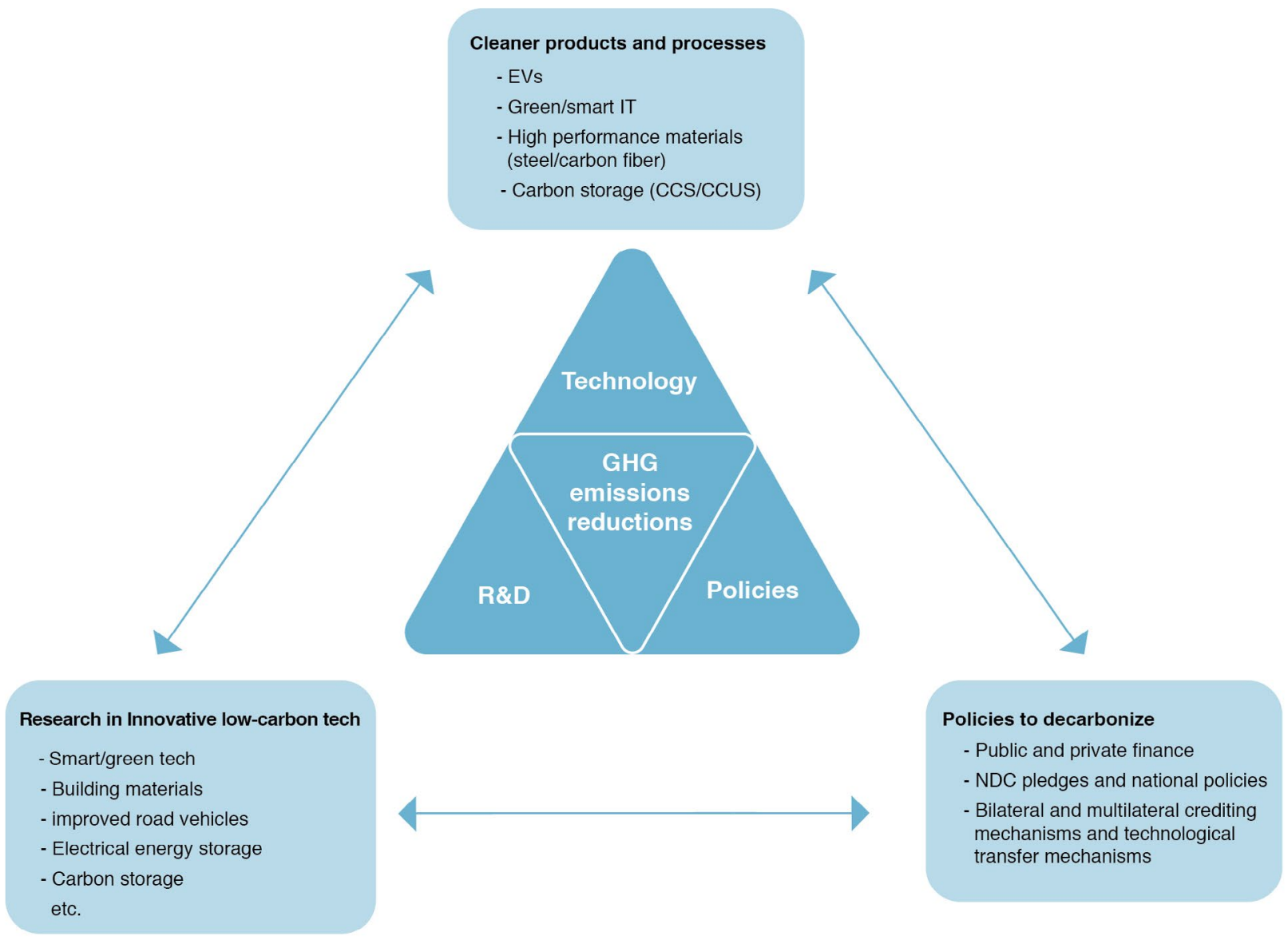

International cooperation and emissions reduction: The global low GHG emitting technological "global commons" 


\section{The role of well-functioning markets consistent with climate goals}

We use the term 'well-functioning markets' to describe those in which policy ensures open access and fair competition for new market entrants. Well-functioning markets also provide accurate price signals and the necessary policy incentives for internalizing climate-related environmental externalities. Price signals combined with policy incentives can provide a meaningful technology-neutral market demand for lowcarbon near-commercial technologies to reach commercialization.

Well-functioning markets, operating within the boundaries set by governments through effective laws, regulations and market rules, can help achieve climate goals. They enable economies to function effectively amid uncertainty and rapid change. Key elements of a well-functioning energy market consistent with the climate goals of the Paris Agreement include:

Aligning accountability and responsibility with role and function such that the party (or parties) best able to manage a particular role has a clear incentive and the necessary authority to do so, in a timely and effective manner and at least cost.

Establishing effective exchanges for physical delivery and financial instruments that facilitate efficient price formation and risk management.

Establishing an effective market structure that promotes transparency and encourages efficient, competitive behavior.

Implementing effective economic and competition regulation, especially for network services.

Ensuring access to timely and accurate information to help inform effective decision-making.

Providing a price signal that reflects a given technology's contribution to climate impacts and policy incentives.

Attributes of well-functioning electricity markets might include the removal of direct and indirect subsidies to existing market participants and related resource inputs, regulations for new interconnections to the grid that are transparent and do not pose an undue burden or barrier to entry, electricity dispatch rules that do not favor existing participants, and a GHG tax or a similar market mechanism.

Governments have a crucial role in establishing the legal, regulatory and market framework as well as policy incentives whenever necessary that set the boundaries for a well-functioning market in whatever 'commodity' is being traded. The framework can be amended, as technology develops and unforeseen strategies emerge that capture rents within it, so that it does not become a barrier to the efficient and innovative operation and development of the energy sector.

\section{Well-functioning markets are dynamic, adaptable and deliver clear price signals}

Such markets are inherently dynamic, evolving in response to changes in technologies, market innovations, consumer tastes and public policy requirements. This inherent adaptability enables markets to continue to function effectively at times 
of uncertainty and rapid change. They can adapt to the challenges and unknowns inherent in the long transition toward a zero-GHG economy in an efficient and timely manner, and at least cost.

Not all economies are liberalized competitive market economies. However, even some of those that rely on high degrees of central planning, particularly China, are experimenting with market mechanisms as a tool to drive reductions in GHG emissions. Well-functioning markets provide scope to create property rights, which can be used to drive the formation of efficient price signals to give individual buyers and sellers strong incentives to develop the most efficient and innovative ways to meet climate change goals at least cost. Well-functioning markets also provide clear price signals for investments in energy efficient end use, a fundamental requirement for continuing to deliver access to reliable and affordable energy services during the transition.

Investors value predictable policy, especially given the long useful life of capital investments in electricity generating capacity and large industrial process equipment, such as in refining, chemicals and steel-making. Investors need a long-term, consistent price signal that reflects a technology's contribution to climate impacts, with policy incentives whenever necessary, to have the confidence to invest in innovative, low-carbon technology.

\section{Funding technological R\&D and the development of new intellectual property}

There is clearly a need for accelerated innovation in the energy sector, and the potential for innovative technologies is both broad and deep, including some options that seem like long shots today. Table 1 includes some examples.
The development of new and low-cost technologies is critical in the long run for reducing $\mathrm{CO}_{2}$ emissions and meeting the $2^{\circ} \mathrm{C}$ target agreed in Paris. Research, development, demonstration and deployment policies create a positive feedback cycle, attracting private sector investment in $R \& D$, which in turn further reduces costs and provides additional incentives to use the relevant technologies. Nevertheless, a demonstrated market demand for low-carbon technologies - evidenced by the commercialization of existing near-term lowcarbon technologies - is crucial to fully mobilizing private sector investment in R\&D. Without this clear market demand, together with policy incentives for low-carbon technologies and an expectation of commercializing a nascent technology at a later stage, private investors will be reluctant to invest in $R \& D$ in the first place.

\section{Technology transfer and the temporary overshoot of the $2^{\circ} \mathrm{C}$ target}

Effective policies would also promote the deployment of low GHG-emitting technologies by helping to overcome the barriers that currently hold it back. The reduced cost of these technologies will strengthen the economic case for their adoption in the developing world, contributing to the successful transfer of technology from developed to developing economies. However, the time spent developing these new technologies may mean that we initially overshoot the 450 parts per million (ppm) scenario. Nevertheless, the technology should enable us to return to the $2^{\circ} \mathrm{C}$ track within a few decades.

This scenario will help realize the $2^{\circ} \mathrm{C}$ target in a way that minimizes the total burden on society including mitigation, abatement, adaptation and damage costs. It will also enable economic growth while addressing climate change. 
Table 1. Technology innovation 'moon shots.'

\begin{tabular}{|c|c|c|c|}
\hline \multicolumn{2}{|l|}{ Technologies } & \multirow{2}{*}{$\begin{array}{l}\text { Description } \\
\text { Fourth-generation nuclear } \\
\text { reactors, including very } \\
\text { high temperature and fast } \\
\text { reactors, are being developed } \\
\text { internationally. }\end{array}$} & \multirow{2}{*}{$\begin{array}{l}\text { Challenges } \\
\text { Expanding support for research and } \\
\text { the development of next-generation } \\
\text { nuclear reactors. }\end{array}$} \\
\hline $\begin{array}{l}\text { Technologies to reduce } \\
\mathrm{CO}_{2} \text { emissions }\end{array}$ & $\begin{array}{l}\text { Next-generation nuclear } \\
\text { reactors }\end{array}$ & & \\
\hline & Nuclear fusion & $\begin{array}{l}\text { Technology for fusing } \\
\text { hydrogen and other elements } \\
\text { with small atomic numbers } \\
\text { to create energy as the sun } \\
\text { does. Deuterium, as a nuclear } \\
\text { fusion fuel, is abundant and } \\
\text { universal. Nuclear fusion does } \\
\text { not emit spent fuel as high-level } \\
\text { radioactive waste. }\end{array}$ & $\begin{array}{l}\text { Technology for continuous nuclear } \\
\text { fusion and containing it in a fixed } \\
\text { space, reduction of the energy } \\
\text { balance and costs, building } \\
\text { fundraising and international } \\
\text { cooperation systems for large-scale } \\
\text { technology development. }\end{array}$ \\
\hline & Space photovoltaic (SPS) & $\begin{array}{l}\text { Technology for implementing } \\
\text { solar photovoltaic electricity } \\
\text { generation in outer space with } \\
\text { more abundant sunlight than } \\
\text { on Earth, and for transmitting } \\
\text { generated electricity through } \\
\text { microwaves wirelessly to earth } \\
\text { for use on the ground. }\end{array}$ & $\begin{array}{l}\text { Developing wireless transmission } \\
\text { technology, reducing costs for } \\
\text { transporting construction materials } \\
\text { to outer space. }\end{array}$ \\
\hline \multirow[t]{2}{*}{$\begin{array}{l}\text { Technologies to sequester } \\
\mathrm{CO}_{2} \text { or to remove } \mathrm{CO}_{2} \\
\text { from the atmosphere }\end{array}$} & $\begin{array}{l}\text { Hydrogen production and } \\
\text { usage }\end{array}$ & $\begin{array}{l}\text { Producing hydrogen by } \\
\text { converting fossil fuels through } \\
\text { steam reforming. } \mathrm{CO}_{2} \text { emissions } \\
\text { are subjected to carbon capture } \\
\text { and storage technology to make } \\
\text { hydrogen production free from } \\
\text { carbon. }\end{array}$ & $\begin{array}{l}\text { Cutting hydrogen production costs, } \\
\text { improving hydrogen production } \\
\text { efficiency, developing the necessary } \\
\text { infrastructure. }\end{array}$ \\
\hline & $\begin{array}{l}\mathrm{CO}_{2} \text { sequestration and } \\
\text { usage }(\mathrm{CCU})\end{array}$ & $\begin{array}{l}\text { Producing carbon compounds } \\
\text { as chemical materials from } \\
\mathrm{CO}_{2} \text { with electrochemical, } \\
\text { photochemical, biochemical } \\
\text { and thermochemical methods } \\
\text { to eliminate } \mathrm{CO}_{2} \text { from the } \\
\text { atmosphere. }\end{array}$ & $\begin{array}{l}\text { Substantially improving } \mathrm{CO}_{2} \\
\text { volumes for capture, effective use } \\
\text { and efficiency. }\end{array}$ \\
\hline
\end{tabular}

Source: IEEJ. 


\section{Conclusions}

Climate change is a 'wicked problem' that requires a realistic approach to its multiple dimensions

In the terminology of social scientists, 'wicked problems' are multidimensional challenges that are difficult to resolve. Climate change is one such challenge. Our limited understanding of its likely impacts suggests the need for a flexible and adaptable policy approach that can rapidly respond to an evolving understanding of the science, to technological advances, to changes in costs and market-based innovation, and to evolving public expectations. A pragmatically flexible, adaptable and ultimately affordable approach will necessarily involve a degree of adaptation and a recognition that some damage may be inevitable. Governments have a leading role to play here to support an efficient, innovative, timely and least-cost response that balances all the goals of the U.N. SDGs.

The approach proposed in this paper means redoubling our efforts to drive a low-GHG transition that delivers lower-cost energy for the world's economies and underpins greater social welfare for all. 


\section{References}

Climate Change Technology Centre and Network (CTCN). 2019. https://www.ctc-n.org/.

International Council of Chemical Associations (ICCA). 2013. "Addressing the avoided emissions challenge: Guidelines from the chemical industry for accounting for and reporting greenhouse gas (GHG) emissions avoided along the value chain based on comparative studies." Accessed Feb. 3, 2019 https://www.icca-chem. org/wp-content/uploads/2015/08/Addressing-the-Avoided-Emissions-Challenge.pdf.

International Energy Agency (IEA). 2017. "Energy Access Outlook 2017."

United Nations Environment Programme (UNEP). 2018. "The Emissions Gap Report 2018." Nairobi, Kenya.

United Nations Framework Convention on Climate Change (UNFCCC). "Technology Executive Committee." http://unfccc.int/ttclear/tec.

World Bank. 2019. "World Bank Development Indicators."

World Steel Association (WSA). 2018. "Fact sheet: Climate change mitigation by technology, innovation and best practice transfer." Accessed Feb. 3, 2019. https://www.worldsteel.org/en/dam/jcr:0191b72f-987c-4057a104-6c06af8fbc2b/fact_technology\%2520transfer_2018.pdf. 


\section{About the Authors}

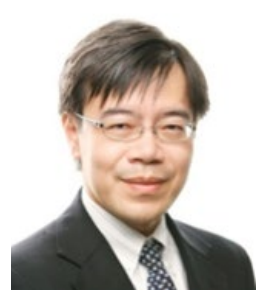

\section{Keigo Akimoto}

Keigo is a Chief Researcher at the Research Institute of Innovative Technology for the Earth and the Leader of its Systems Analysis Group. $\mathrm{He}$ is a member of several advisory bodies on energy and environmental policy for the Japanese government. He is also an Associate Member of the Science Council of Japan.

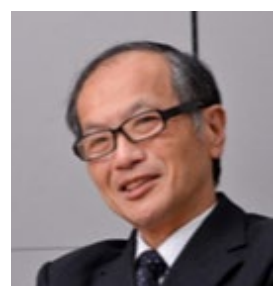

\section{Jun Arima}

Jun is a Professor at the Graduate School of Public Policy, University of Tokyo. He has been a Counselor at the Japanese Delegation to the Organization for Economic Cooperation and Development (OECD), and Head of the Country Studies Division at the International Energy Agency. He participated in the United Nations Framework Convention on Climate Change (UNFCCC) negotiation as a chief negotiator.

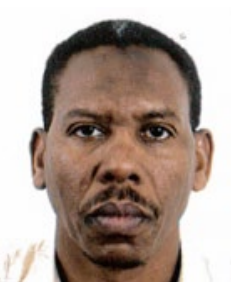

\section{Mustafa Babiker}

Mustafa is currently a senior analysis and planning consultant with Saudi Aramco and a research associate of the Massachusetts Institute of Technology (MIT) Joint Program on the Science and Policy of Global Change. Mustafa previously worked for MIT and the Arab Planning Institute.

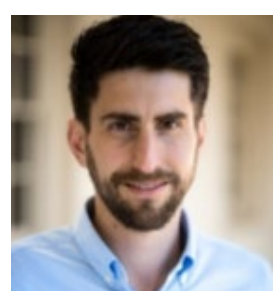

\section{Mark Caine}

Mark Caine is Government Affairs Lead at the World Economic Forum's Centre for the Fourth Industrial Revolution. He was formerly Special Adviser for Infrastructure and Energy at the African Union Commission, and Policy Adviser for Energy and Environment at the United Kingdom's Foreign and Commonwealth Office. 


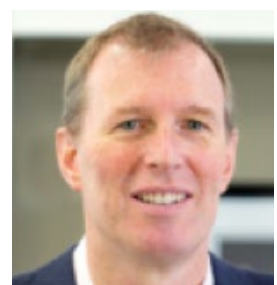

\section{David Hobbs}

David Hobbs was formerly KAPSARC's Vice President of Research, having previously served as Chief Energy Strategist and Head of Research at what is now IHS Markit. Prior to joining IHS Markit, David spent nearly two decades in the oil and gas industry, predominantly in Europe, the Americas and Asia.

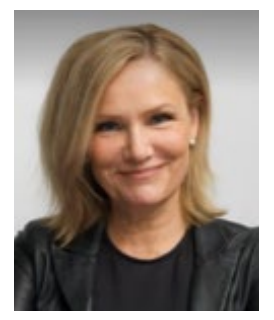

\section{Eija-Riitta Korhola}

Eija-Riitta is a former Member of the European Parliament (MEP) (1999-2014) and a specialist in communication and consultancy in European Union affairs. She is currently a Delegate of the Consultative Commission on Industrial Change (CCMI) at the European Economic and Social Committee in Brussels.

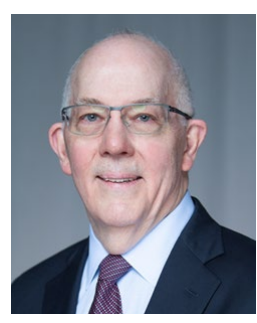

\section{Adam Sieminski}

Adam Sieminski is the president of KAPSARC. Before joining KAPSARC in early 2018, Mr. Sieminski held the James R. Schlesinger Chair for Energy and Geopolitics at the Center for Strategic and International Studies (CSIS). He served as the administrator of the U.S. Energy Information Administration (EIA) from 2012 to 2017, after a long career as a financial analyst following energy and commodities issues on Wall Street.

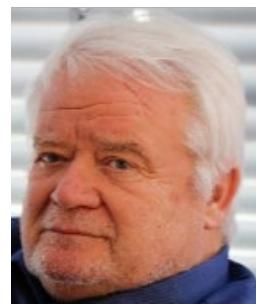

\section{Nico Stehr}

Nico is Senior Fellow of the Institute for Advanced Sustainability Studies, Potsdam, Germany, a fellow of the Royal Society (Canada) and a fellow of the European Academy of Sciences and Arts. He is one of the authors of the set of Hartwell papers on climate policy. 


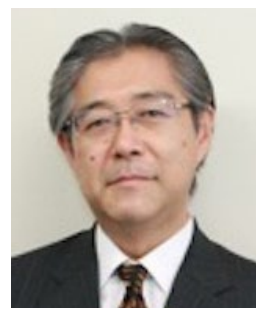

\section{Hiroyuki Tezuka}

Mr. Tezuka is General Manager, Climate Change Policy Group at JFE Steel Corporation, and the Chairman of Working Group on International Environmental Strategy, KEIDANREN (Japan Business Federation). Since 2007, Mr. Tezuka has been in charge of Climate Change issues and involved in environmental and energy policy.

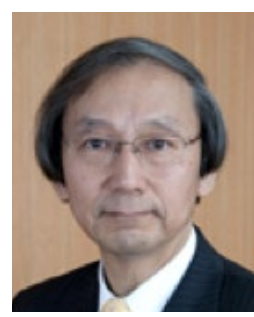

\section{Masakazu Toyoda}

Masakazu is Chairman and CEO at the Institute of Energy Economics (IEEJ), Japan. He is also an adviser to the King Abdullah Petroleum Studies and Research Center (KAPSARC), Accenture, the Oxford Institute for Energy Studies (OIES), the Pacific International Center for High Technology Research Center (PICHTR), and the Brunei National Energy Research Institute (BNERI).

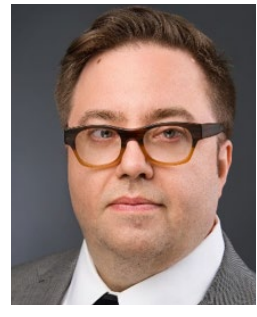

\section{Eric Williams}

Eric is the acting director of the climate change and environment (CCE) program at KAPSARC. He was formerly with the North Carolina Utilities Commission, the OECD, the International Atomic Energy Agency (IAEA) and several think tanks.

\section{About the Project}

The paper explores policy options for expanding the role of technology as a potential enabler to achieve climate goals. It is based in part on a series of workshops held in Tokyo, London, Washington, and Riyadh. 
INAPSARC

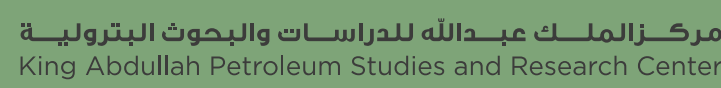

www.kapsarc.org 